\title{
Hacia una teorización del carnaval performance: el carnaval de Blancos y Negros de Nariño ${ }^{1}$
}

\author{
Julio César Goyes Narváez ${ }^{2}$ \\ Universidad Nacional
}

\section{Resumen}

Este ensayo propone, en primer lugar, una programática plataforma conceptual que intente acercar el carnaval al performance como línea de estudio interdisciplinaria. El performance se entiende como competencia y habilidad y, más allá del saber-hacer y el saber-decir, como un saber-estar en el tiempo y en el espacio, donde el cuerpo y la razón son envueltos y gozados: por ello los espectadores dejan de estar frente $a$, para situarse en o dentro de. En segundo término, propone resitúar el carnaval como una de las manifestaciones populares más visibles, intercultural y multiexpresiva, que es preciso, desde la academia y la investigación social y humana, activar como campo de estudio, redefiniendo su estética y su sentido frente a los cánones

\section{Abstract}

This essay proposes, in the first place, a programmatic conceptual platform that tries to approach the carnival the performance as interdisciplinary line of study; the performance is understood like competition and ability and, beyond know-doing and know-saying, like knowbeing in the time and the space, where the body and the reason are surrounded and enjoyed, for that reason the spectators they let be as opposed to, to locate itself in or within; and in second term, to resotúar the carnival like one of popular but visible the manifestations, intercultural and multiexpressive, that are precise from the academy and the social and human investigation, to activate as field of study, redefining its aesthetic and its sense as opposed to the western

\footnotetext{
${ }^{1}$ Este texto fue leído como ponencia en el II Encuentro Internacional de Fiesta, Cultura y Nación, que tuvo lugar en el Archivo General de la Nación, Bogotá, del 13 al 16 de marzo del 2008, organizado por el IECO de la Universidad Nacional.

${ }^{2}$ Licenciado en Filosofía de la Universidad del Cauca y Magíster en Literatura Hispanoamericana del Instituto Caro y Cuervo. Profesor e investigador de las Universidades Javeriana y La Salle. e-mail: cgoyes@hotmail.com
} 
occidentales del arte y la cultura, validando así su aporte a la dimensión simbólica de la historia nacional.

Palabras clave: carnaval, performance, cronotopo, cuerpo, escenario. canons of the art and the culture, thus validating its contribution to the symbolic dimension of national history.

Key words: Carnival, Performance, Chronotopos, Body, Stage.

El carnaval no es como la vida, es la vida: muere y resurge como la luna en gritos de silencios, máscaras de carnaval.

\section{Una pintica}

Establezcamos las coordenadas, el referente de este texto es el carnaval y uno en particular, el de Blancos y Negros, de Nariño, Colombia. Se advertirá de inmediato que estoy pulsando desde la región y no desde lo local. Es decir, no es únicamente en la ciudad de Pasto, capital de departamento, donde se celebra el Carnaval de Blancos y de Negros, sino en varias ciudades y/o poblaciones nariñenses. Esta aclaración es pertinente para mis estudios sobre las imágenes del carnaval por cuanto alimenta varias miradas, estableciendo contrastes, diferencias y semejanzas entre los distintos carnavales que acontecen en las mismas fechas en la región del sur.

Tal vez deba agregar otra coordenada, que tiene que ver con el estilo, tendencia o modelo, para hablar desde la tensión entre modernidad y posmodernidad. Entre un carnaval y otro crece cada día una rejilla mediática, política y económica difícil de salvar, pues si son experiencias culturales diferentes, ¿por qué unas se vuelven excluyentes y se legitiman como únicas? Prueba de ello es la forma como los noticieros de televisión y los periódicos vuelven noticia y documentalizan "los carnavales de Pasto", instalándose en lo local y olvidando el territorio festivo regional que es diverso y por ello imagen compleja de nación. Hay sin duda intervención política y comercial, como políticos son los carnavales (qué duda cabe), pero una cosa son los intereses del gobierno que interceden como parte de su programa político de partido, y al interceder se sostiene en el poder, y otra muy diferente la sorna carnavalesca tan crítica como efímera, pues su poder es entrópico y no molar. ¿Qué pasa cuando las administraciones municipales y gubernamentales participan de manera directa o sesgada en la organización y gestión del carnaval, decidiendo en más de un aspecto sobre su forma y contenido? Sin duda, tema de otro estudio. 
Varios artesanos de Ipiales se van el 6 de enero a participar a Pasto, dejando un vacío festivo y estético a veces difícil de llenar en la ciudad de las "Nubes Verdes". Van a la Capital por el simple hecho de que en la capital nariñense los premios a las carrozas y comparsas son mejores, con el agregado de que allá pueden ser vistos por un "gentío de gente", como dicen los vecinos, refiriéndose a la participación masiva de visitantes y turistas, sin olvidar los agentes de la televisión nacional que jamás van a Nariño sino a Pasto, pues desconocen la colcha de retazos que se enreda en el sur. Los medios siguen repitiendo el mote histórico sin comprender la etnohistoria, aquel mote donde todo nariñense sigue siendo pastuso. Así las cosas, ya no podemos hablar de la participación ritual, de la genuina alteración o instauración del desorden en pro de renovación alguna. Ahora son los premios, lo apoyos y las financiaciones comerciales los que dirigen la calidad de lo que los artesanos presentan y representan. Sin duda aquí está la mano del diablo, pero no de ese que extasía y limpia como en el carnaval de Ríosucio, sino de esa necrosis que se llama capitalismo salvaje y neoliberalismo, que alcanza hasta lo lúdico dirigiendo el goce y que, no contento con disciplinar los cuerpos, los horada hasta succionar sus conciencias.

Dos coordenadas finales: por un lado, espero que el alcance de los planteamientos que a continuación expongo sirvan para motivar la reflexión general aplicada a todo carnaval (andino, caribeño, de fronteras), no sin encontrar en ello las especificidades que cada práctica y saber carnavalesco posee; y por otro, proponer la diversidad y oponerse al centralismo que promueven los agenciamientos del poder a través de los medios de comunicación, pues la diversidad en mis términos es la verdadera y única nación, donde "emerge un desorden cultural que cuestiona las invisibles formas del poder que se alojan en los modos del saber y del ver, al tiempo que alumbra unos saberes-mosaico, hechos de objetos móviles, nómadas, de fronteras difusas, de intertextualidades y bricolajes" (Barbero y Rey, 1999: 12). En ese sentido hay que defender la diversidad y la complejidad de la cultura popular y no la "unidad" homogénea y abstracta de la patria, simbología masiva con la que algunos de los dirigentes imponen su patria.

Estos rasgos comparativos y diferenciadores que ayudan a construir una visión de la cultura popular nariñense multiexpresiva e intercultural, y las dinámicas que atraviesan nuestras identidades articuladas a las industrias culturales, sin las cuales no podríamos hoy pensar y vivir las culturas populares, no son objeto principal de la reflexión del presente ensayo y quedan apenas soslayadas al estudiar el carnaval y el performance. 
Ahora ya estamos con la pintica en el rostro, tal vez incómodos, o a lo mejor dispuestos a entrar en el juego yo te pinto y tú me pintas, un traguito y comencemos a pintar y bolear talco a todo el que por allá y por aquí pasa.

\section{Máscaras}

Durante varios meses del año el ritmo de vida de los nariñenses, como también de los colombianos, está regido por la linealidad del trabajo y la rutina. El fin de año es la recompensa esperada a esa prolongada jornada. Por eso quemar un muñeco ("El Año Viejo") no sólo es pretexto para la fiesta, sino regeneración de las fuerzas vitales, ritualización de un conjuro tácito que revisa el pasado y visiona el futuro, pero en un presente inmediato. Luego, siguiendo estos desacomodos iniciados desde las fiestas de "el pase del niño Dios" y acrecentadas el 31 de diciembre, viene el jolgorio de los carnavales, que después de varios días va disminuyendo en el ánimo de sus gentes hasta convertirlas otra vez en figuras regladas socialmente. La interiorización se va haciendo lenta y busca acomodarse en el recogimiento. Pronto los nariñenses, y esta vez coincidiendo con el calendario de todo el país, asistirán a otra transformación, la espiritual. Durante los últimos días de marzo o primeros días de abril comienza una etapa religiosa, de acatamiento, que no tiene ya nada que ver con subvertir las normas. Me refiero a la cuaresma, puesto que se impone no por las formas de convivencia social, sino por una ideología religiosa de corte católico. Después, los hombres y mujeres arrepentidos caen en una modorra o desgano que durará hasta el advenimiento de las vacaciones de mitad de año, que son un alivio esporádico que ayuda a mantener la esperanza y a resistir la monotonía hasta la llegada del fin de año y principio del nuevo. Es en este momento que los nariñenses por fin serán otros, trasgredirán sus formas de ser, de sentir y de pensar, a fin de cambiar sus vidas y encontrar nuevas salidas para el nuevo año. Así se cumple el eterno retorno de una cultura andina colombiana que posee singularidad y que le aporta a la escena nacional no sólo un capital simbólico, sino el registro de saberes y prácticas culturales populares que rompen lo monumental y vuelven efectiva su historia ${ }^{3}$.

\footnotetext{
3 "La significación social del Carnaval se revela por sistemática oposición simbólica a la Cuaresma y a su manifestación apoteósica, la Semana Santa. Mediante la dramatización ritual de dicha oposición, las sociedades señalan el valor que debe concederse a lo que no es ni una cosa ni otra, ni Carnaval, ni Cuaresma, lo que es, en cambio, la vida social ordinaria" (Gutiérrez Estévez, 1989: 34).
} 
Crucemos el umbral, vayamos de la pintica a las máscaras. De la estética de la obra a la estética del proceso ${ }^{4}$. La máscara carnavalesca, por el contrario a lo que normalmente se le designa (como ocultadora de los secretos de la personalidad), actúa como médium para sacar las frustraciones, complejos y dichas; los deseos, en suma. La pintica se torna máscara en el mismo instante en que alguien asume la fiesta en el rostro del otro. El otro puede que al principio se resista, pero el jolgorio dionisiaco lo obliga a ceder, a comulgar con la fiesta. La máscara es ya acción que solapa y provoca la mirada, desplegando el ritual donde la inversión, la ridiculización, la subversión, la transformación de los sexos, del poder político y religioso y la representación de animales (el oso, el gallo, el cerdo, el caballo, el tigre, etc.) van a tener lugar. La ruptura de las normas, de las categorías y las clasificaciones no es posible en el carnaval sin esa mediación física, psicológica y simbólica que denominamos máscara. Por eso la pintica de cosmético es ya la andadura o rastro de la máscara en el rostro; en muchas ocasiones, y para un gran sector de la población, la máscara es un sutil simulacro, pues aun sin pintica y sin artefacto, se ponen la máscara psicológica y entran al carnaval desde sus propias lógicas festivas que pueden ser tan familiares como comunitarias. Sin lugar a dudas, en las fiestas carnavalescas se realizan todo tipo de acciones rituales que tienen en común el representar una inversión o una transformación de la identidad social de los individuos. Con los disfraces, por ejemplo, se cambia el sexo o el oficio, o se parodia la conducta y desempeño de las autoridades, se promueve la exaltación fingida de los más humildes a las posiciones más altas de la jerarquía social (Gutiérrez Estévez, 1989: 35).

El carnaval asiste a todas las posibilidades, decantaciones y visiones. Portalrazónencontramosunaseriededesplazamientoshaciaelteatro, la danza, la poesía, la música, la plástica, la magia y el malabarismo. El carnaval relaciona todos estos lenguajes como si se tratara de un collage (recortes de palabras, gestos, imágenes y acciones), dando vida a un happening o un performance, procedimiento de asimilación nada prevenido y quizá por ello algo ingenuo, fresco. La repetición de procesos ya realizados y la experimentación lleva a la crítica de la especificidad del material que se requiere para armar su forma-

\footnotetext{
${ }^{4}$ No en vano Jesús Martín Barbero, pensando en los desafíos comunicativos que lo popular le hace a la razón dualista, habla de que muchos investigadores en América Latina prefieren perder el objeto para ganar los procesos. Por eso, "el campo de los problemas de comunicación no puede ser delimitado desde la teoría, no puede serlo más que a partir de las prácticas sociales de comunicación, y esas prácticas en América Latina desbordan lo que pasa en los medios y se articulan a espacios y procesos políticos, religiosos, artísticos, etc., a través de los cuales las clases populares ejercen una actividad de resistencia y réplica" (Barbero, 2003: 124).
} 
contenido, para generar un afecto, un efecto, producir comunicación estética, lograr que el espectador recree y reinvente esa estructura signo-simbólica, pero, además, entre en el juego que el carnaval le propone. El espectador es actor y dialoga narrando y siendo narrado, dramatizando y siendo dramático, interpretando y siendo interpretado, todo esto de acuerdo a su referente vital y contexto cultural: el entorno se le aparece y desaparece, le dice o no dice, o le sugiere.

\section{Cuerpos}

La lujuria, la gula, la gordura, los excesos, la agresividad, el "cara a cara irreductible" concentrado en la mirada, el contacto entre los cuerpos, el desplazamiento danzarín y seductor. ¿Qué sería de la pintica si no se construyera enseguida una máscara y, más aún, si el cuerpo no aparece, no se da, no llega? Cuando el cuerpo aparece ya estamos en un "sistema sinestésico", una estética de shock, donde se dan cita, como diría Walter Benjamin, las "energías excesivas". Si hay potencia, y además de sobra, hay expresión, sin duda. Por consiguiente se obtendrán diversas reacciones de los participantes, llámense autores-actores unos, espectadores-receptores, otros. Pero estas reacciones catárticas, rituales, emotivas, dramáticas, son el múltiple resultado de la percepción (vista, tacto, oído, olfato, gusto), del entendimiento que se presenta a partir de los recuerdos y la crítica, de la interacción con las emociones (tristeza, felicidad, expectación, interés, concentración, etc.), de la reacción (sorpresa, fastidio, enojo, felicidad, alteración nerviosa, etc.), para que finalmente el espectador interactúe y exprese todo lo que quiera y pueda (gritos, risas, comentarios, movimientos corporales bruscos, delicados, etc.).

De suerte que ya podemos arriesgar nuestra afirmación principal: el carnaval es un performance, porque como dice Diana Taylor, a propósito de los performances en general, estos funcionan como actos vitales de transferencia, transmitiendo saber social, memoria, y sentido de identidad a través de acciones reiteradas (Taylor, (s/f)). El carnaval performance no intenta convencer a los espectadores; su objetivo primordial es obtener una reacción, poco importa que tan positiva o negativa sea. No obstante, el carnaval performance completa la experiencia estética con la experiencia psicológica, antropológica, sociológica, con la comunicación audiovisual, la hipervisualidad y la tecnopercepción. Por consiguiente, el carnaval performance es un campo de estudio, no sólo histórico, sino técnica de creación que reúne todas las disciplinas del arte tradicional y posmoderno (las artes visuales, la música, el arte escénico, la tradición oral y 
la literatura). El carnaval es un performance y una escuela, lugar fecundo para derivar las ciencias humanas y sociales ancladas en epistemologías estatutarias y monolíticas. Además, atendiendo al llamado de las investigaciones de las neurociencias, podría ayudarnos a comprender cómo funciona la mente en relación a los cerebros y sus hemisferios. Es decir, el carnaval-performance es una línea de investigación completa, porque es el arte en su máxima expresión. Pidiendo prestado las palabras de Ramón Montaño y adaptándolas al carnaval, podríamos decir que es un medio que salva conciencias por medio de la concientización a través de situaciones hasta cierto punto absurdas o surrealistas que despiertan otros estados metales en la conciencia del espectador y que están ligadas directamente a la sociedad en la que vivimos (Montaño, s/f).

El carnaval-performance implica competencia y habilidad: no sólo es un saber-hacer o un saber-decir. La performancia es un saber-estar en el tiempo y en el espacio, pues el referente que lo envuelve, definitivamente, es del orden del cuerpo ${ }^{5}$. Tal vez por eso el psicoanálisis nos recuerda todo el tiempo los instintos, de dónde venimos, qué hacemos, adónde deseamos ir; nos recuerda, en suma, el precio que a veces debemos pagar por olvidarlos o renegar de sus oscuros orígenes ${ }^{6}$.

\section{Visualidades}

El cuerpo en el carnaval no se mueve en abstracto, no se suspende y descontextualiza, no retira el entorno cotidiano como en el teatro o la pintura, que tienen que construir uno a veces demasiado acotado, sino todo lo contrario: el entorno se desplaza, salta y se encoge en un cronotopo especial que es plástico, sí, pero no pieza de museo o galería. Pensemos en las comparsas, los disfraces, las carrozas: colores, texturas, dimensiones hiperbólicas, confecciones geométricas, movimientos robóticos, expresiones vanguardistas. Toda una dimensión sintáctico-formal que clama de inmediato nuestra mirada y enseguida nuestro cuerpo y toda la subjetividad que lo acompaña.

Si cuando aparece el cuerpo asistimos a un performance, con la forma plástica que lo mueve de manera centrípeta y centrífuga, asistimos a un happening. Los límites entre una y otra manifestación estética

\footnotetext{
${ }^{5}$ Nietzsche, si mal no recuerdo, visionaba que la historia efectiva y no la monumental, así como el lenguaje, están atravesados por el cuerpo.

${ }^{6}$ Freud, en una carta reveladora a uno de sus amigos, escribe: "los hombres siempre han sabido que tenían un espíritu, a mí me correspondía mostrarles que también tienen instintos" (Marthe, 1972: 67).
} 
están cubiertos por una neblina conceptual cuyo discurso se aclara o desvanece en la abscisa discursiva modernidad/posmodernidad. Además, no es este el lugar para una profundización de ese orden y no hace parte de este ensayo, no obstante, digamos que el performance engloba desde los principios dadaístas de 1916 al happening, forma privilegiada del neodadaismo que aparece como una reacción a las artes tradicionales casi cuatro décadas después. Si el uno es más táctil y corporal, el otro será más visual. En una apreciación sobre el happening que hace Simón Marchán Fiz podemos encontrar más semejanzas que diferencias: "ya no se trata de ennoblecer estéticamente la realidad, sino de ampliar lo estético a nuevos elementos que pueden encontrarse en la calle, en las plazas, en nuestro medio cotidiano y que no experimentan una estructuración artística consciente" (Marchán Fiz, 2001: 193).

Si happening responde a la intención de apropiar directamente la vida a través de una acción, interviniendo la realidad. Pero, ¿acaso no es eso también el carnaval-performance? Se me argumentará de inmediato que una diferencia esencial con respecto al carnaval es su espontaneidad, quienes lo hacen y lo viven no parten de una intencionalidad artística. Esto en apariencia puede ser lógico, pero jamás será verdadero. La cultura elitista y oficial quiere ver irracionalismo y desorden en las manifestaciones artísticas populares; sin embargo, quienes participan del carnaval, además de su espontaneidad ritual, quieren también impactar, agradar, figurar, conmocionar, ser aplaudidos, ganar un premio. Quieren, en suma, reconocimiento. Para ello se valen de muchos recursos visuales, de conocimientos ancestrales y técnicas tradicionales, de muchos materiales, de distintas formas comunicativas y múltiples experimentaciones. En el carnaval nadie sale a las calles sino tiene la seguridad de que va a ser visto, padecido, criticado, aplaudido, reconocido.

La composición del carnaval-happening-performance tiene que ver, por lo menos, con dos aspectos que se yuxtaponen y cambian al azar: uno de ellos es la estructura, que es abierta y por lo tanto no predeterminada, aunque se basa en unas ideas de acción que evolucionan en pleno proceso (es decir, cuando los actores del carnaval ya están en escena). Nada tiene que ver con el guión, a menos que lo entendamos como una simple guía. El otro aspecto es la materialidad, pues cualquier estímulo sensible de un acto cotidiano, (cosas, colores, texturas, objetos o fragmentos de algo), pueden devenir materiales y estética carnavalesca. Esto ocurre cuando los danzarines, los comediantes, los disfrazados, las comparsas, las viudas, las murgas, los imitadores, etc., ensamblan y montan lo que a 
su imaginación ha llegado durante horas en soledad o en colectividad y lo que tienen que decir-hacer, porque si no lo dicen-hacen se frustran hasta el próximo año. El "principio del collage", tan antiguo como la recursividad humana, tan moderno como los relatos fragmentados de la ciudad, se da cita en el proceso artesanal que deviene carnaval. Pero aquí ese puzzle no escinde al sujeto apartándolo de la fiesta, sino que lo trama o teje a la unidad del axis mundi.

El carnaval-performance-happening provoca en los espectadores, los paseantes, los distraídos, una intensificación de la atención y de la capacidad consciente de la experiencia, suscita una especie de irritación y provocación de las costumbres convencionales de la experiencia perceptiva y creativa, en su renovación como en su reiteración. Es decir, se recrea, transforma y se amplia la percepción en el espectador que primero es sorprendido (afecto) y luego salta al interior de un distanciamiento (efecto), que es desde donde miraparticipa y lentamente valora y evalúa la experiencia de lo que frente a sus ojos está ocurriendo: o bien, es un ritual y una magia, o bien es una acción política, o quizá es todo eso, un fluir de la dimensión colectiva del gozo.

\section{Escenarios no convencionales}

Las calles, la plaza, la casa: experiencias subjetivas y colectivas donde la vida misma, la vida concreta, alcanza esplendor, pues el sentido del carnaval no es espectáculo teatral representado en un escenario convencional con actores y espectadores, sino vivido en el cronotopo (tiempo-espacio) del carnaval. "Los espectadores no asisten al carnaval, sino que lo viven, ya que el carnaval está hecho para todo el pueblo. Durante el carnaval no hay otra vida que la del carnaval. Es imposible escapar, porque el carnaval no tiene ninguna frontera espacial. En el curso de la fiesta sólo puede vivirse de acuerdo a sus leyes, es decir de acuerdo a las leyes de la libertad" (Bajtín, 1974:13). El cronotopo no únicamente se performa en las esquinas, pues cualquier lugar que clame la atención de los actores del carnaval se convierte inmediatamente en escenario, escenario abierto, insistamos, no convencional, pues todo sucede o está a punto 
de suceder ${ }^{7}$. La acción carnavalesca se da como presentación más que como representación. La performance es tan comprometida con la gente que mira-participa, que ésta última termina involucrada en lo que ese fragmento-totalidad de carnaval le propone. Los escenarios son los espacios y tiempos cotidianos, normales, de todos los días, pero esta vez excedidos por el cronotopo de las máscaras que no se veían o que se habían olvidado: pues el sentido de la fiesta es hacer visible lo invisible, como la poesía, desarticular las abstracciones y prácticas que separan el espacio del tiempo, sin olfatear que el tiempo es la cuarta dimensión del espacio.

Retomemos apartes anteriores para derivarlos un poco más. Digamos, por ejemplo, con Susan Back Mors que, al revisar un artículo de Walter Benjamin, descubre que "el campo original de la estética no es el arte, sino la realidad - la naturaleza corpórea y material (...) Es una forma de cognición, que logramos a través del gusto, el tacto, el oído, la vista y el olfato- todo el sensorium corporal" (Sarikartal, 2005: 105). De suerte que hay un "sistema sinestésico" que se activa cuando se encuentran las imágenes interiores de la memoria (aquellas experiencias anteriores: carnavales y fiestas pasadas, información nueva, cotidianidad, etc.) con los estímulos exteriores (el carnaval nuevo que prolifera por todas partes). Esta sinestesia en principio causa un shock que, en términos de Benjamin, serían "energías excesivas" que construyen los escenarios. Tres entonces son los componentes: primero, una sensación física; segundo, una reacción motora; y tercero, un significado psíquico, yo diría, un sentido cuya carga subjetiva amenaza con desestabilizar los lenguajes y experiencias de la razón, sus lógicas y gramáticas socioculturales.

Los escenarios callejeros del carnaval son definitivos para construir una mirada performática. Ya Walter Benjamin (1973), analizando la obra de arte moderna que ha perdido el aura y clama en la era de la reproductibilidad técnica para no desaparecer, había observado que en la abscisa modernidad/posmodernidad esta obra de arte

${ }^{7}$ El concepto de cronotopo lo retomó M. Bajtín de la teoría de la relatividad (Einstein), pero lo derivó como metáfora de la forma y el contenido en las relaciones espacio-temporales asimiladas artísticamente en la literatura. "El cronotopo, como materialización principal del tiempo en el espacio, constituye para la novela un centro de concreción plástica, de encarnación. Todos los elementos abstractos de la novela -generalizaciones filosóficas y sociales, ideas, análisis de causas y efectos, etc.- tienden hacia el cronotopo y adquieren cuerpo y vida por mediación del mismo, se implican en la expresividad artística" (Bajtín, 1996: 68). El propio Bajtín estudió el cronotopo en el carnaval popular medieval para observar cómo la novela de François Rabelais lo había asimilado y lo metaforizo en la esquina como lugar de encuentro y desencuentro. 
se experimentaba de dos formas: una puramente visual que exige concentración, pues para asumir su significado es preciso escudriñar la forma y su estructura (la obra de arte para el museo, por ejemplo); otra, que es percepción visual/táctil, ante todo táctil. Se puede experimentar en la distracción, pues las masas se distraen en su entorno y allí, sólo allí, pueden ser capturadas por la experiencia estética. Indudablemente, esta última es una experiencia arquitectónica, urbana, citadina.

En el carnaval-performance la dicotomía arte-no arte se fuerza a desaparecer o, por lo menos, se inclina al olvido, mediante la integridad de todos los materiales inimaginables con todas sus relaciones posibles. Los espectadores cesan de estar frente $a$, para situarse en o dentro de.

\section{Audiovisualidades}

Cada acción, disfraz individual, disfraz por pareja, comparsa, murga, carroza, grupo de carnavaleros que pasan pintando, anudando con carioca o talco a los espectadores, son fragmentos que cada espectador-receptor, convertido en actor-autor-participante, monta como un audiovisual, pero uno muy particular, que no se escribe o edita a distancia, sino en el acto mismo en que sucede. Incluso, cuando la televisión regional registra y narra el evento, cada espectadoractor se reconoce diferente dentro de ese escenario y ese relato que cuenta, hasta el punto de verse no como en un reality, cuya imagen es devuelta "real", pulsando por convertirse en algo siniestro: la imagen que la televisión le devuelve al carnavalero es simbólica, eficaz. Por eso, cuando se trasmite un carnaval, por formal que sea la transmisión, el televidente no puede evitar imaginar estar en el carnaval. Su murmullo es "vamos a la plaza, salgamos" o "hay que ir el próximo año: no puedo perderme eso". La imagen que le devuelve el televisor es una imagen extraña e inquietante, una imagen que clama por repetirse, por salir del fondo. Por eso se ritualiza en la actuación-vivencia (sobreactuación) como normal en lo anormal, pues entre más estrafalaria y terrible más normal de cara al carnaval, más, digamos, carnavalesca. La experiencia frente a la pantalla es limitada y en más de un punto frustrante. Por eso el performance del carnaval en situ es formativo y si me apuran, educativo.

Aquí estamos frente a una terapia del orden del deseo, justo cuando el inconsciente flota en lo siniestro al filo de cada año, así mismo cada año se aplaca y desvanece: las máscaras de carnaval, con sus actores y escenarios, permiten fusionarse, no confundirse (el juego del otro y el mismo), en una especie de "si yo soy culpable, ustedes también", 
"todos lo hemos hecho". La "horda" es culpable, pero se libera porque purga en Blancos y Negros por varios días. El Axis mundi se regenera, el sujeto sana la fisura con la realidad que lo oprime y, por largos instantes, deja de estar escindido. El tiempo es así embalsamado en el carnaval que se muestra tan sobredimensionado como efímero. La contingencia de la vida ha sido burlada, pero vuelta a asumir en el inconsciente que carga el carnaval-perfomance, aquel que enfrenta en todas sus simbologías y representaciones a la muerte, escapándose una vez más y prolongando la vida y el deseo de ser otro al tiempo que el mismo, hasta el próximo año.

\section{La pintica final}

No hemos discutido aquí el concepto de performance porque ese no es nuestro objetivo, tampoco nos hemos agarrado de una única definición, y menos cambiado la palabra por otra simple como "acción”, "transformación”, "provocación”, “inclusión”, "participación”, "comunión", “comunicación", "defensa", "protesta", "indignación"... "intervención"... No lo hacemos simplemente porque performance es todo eso o significa mucho más y por ello no tiene traducción -creo que en ninguna lengua occidental la tiene-. Tal vez los significados se acerquen más cuando nos aproximamos a las lenguas indígenas, pero eso es harina de otro costal. Lo que me interesa destacar en este texto programático de investigación es que si bien se retoma el carnaval por su práctica, historia, su impacto mediático o relax social, cuyo valor como objeto es la diversión, el turismo o el ocio, es urgente y por ello necesario - la convocatoria al II Encuentro Internacional de Fiesta, Cultura y Nación celebrado en Bogotá del 13 al 16 de marzo del 2008 y organizado por el IECO de la Universidad Nacional podría demostrarlo-, el considerar al carnaval desde miradas que abran caminos para estudios teóricos e investigaciones que empoderen las estéticas de la cultura popular. Entre otras cosas, porque es necesario inscribir nuestras fiestas dentro de lo que García Canclini denominó, en su momento, "culturas hibridas", o Ticio Escobar: "Trama espesa de transculturaciones, apropiaciones y modernidades paralelas" (Escobar, 2003: 298). Así podemos evitar ser evaluados, valorados y asimilados por la historia, la crítica y la teoría del arte clásico y moderno que no puede ver otra cosa que una 
manifestación que imita lo artístico o, cuando es benevolente, habla de una arte vulgar, kitsch, masivo ${ }^{8}$.

Si atendemos a lo estético que tramita la forma, como a lo poético que discurre el sentido, podemos verificar que ambas características están presentes en manifestaciones simbólicas de las culturas populares como el carnaval. No obstante, la estética moderna niega la propiedad "artística" porque no cumplen con sus exigencias, "ni logran independizar lo estético (pese a que ajustan la forma para que sostenga ella mejor los contenidos sociales), ni son fruto de una creación individual absoluta (aunque cada artista reinterprete a su modo los inveterados códigos colectivos), ni se producen a través de innovaciones transgresoras (a pesar de que su desarrollo suponga una constante movilización del imaginario social), ni se manifiestan en obras irrepetibles (aun cuando cada forma específica debe haber conquistado su propia capacidad expresiva y estética)" (Escobar, 2003: 284).

Las preguntas son ¿cómo se dio la experimentación a que fue sometido el arte clásico para entrar en la modernidad y consolidarse en las vanguardias? ¿Qué papel juegan las fiestas carnavalescas, religiosas y políticas en la des-estructuración del arte serio, de museo o de galería? ¿Se renuevan o no las instituciones sociales con las celebraciones festivas y, si lo hacen, cómo lo hacen? ¿Le pasa algo a los sujetos después de vivir una fiesta popular como el carnaval? ¿Qué le aporta la fiesta, por ejemplo el carnaval, a la imagen de nación? ¿Al crear el carnaval expresiones efímeras cuestiona el consumo artístico capitalista, critica la industrialización del arte o, simplemente, ritualiza prácticas y saberes ancestrales, tradicionales, comunales? ¿Qué pasa cuando a las organizaciones festivas ingresan los espectáculos mediáticos y las industrias culturales? ¿Qué le ocurre a la expresión y comunicabilidad de las obras cuando los participantes-artesanos-artistas no pueden resistirse a las estéticas masivas y se ven obligados a reciclar sus formas, su contenido y sus espectáculos? ¿Hasta dónde el carnaval puede mirarse desde

\footnotetext{
${ }^{8}$ Ya sabemos que cultura popular que lucha contra los poderes hegemónicos no es lo mismo que cultura de masas, bandera del capitalismo salvaje. "Las culturas populares son resultado de una apropiación desigual del capital cultural, una elaboración propia de sus condiciones de vida y una interacción conflictiva con los sectores hegemónicos. Al comprenderlas de este modo, nos alejamos de las dos posiciones que han predominado en su estudio: las interpretaciones inmanentes, formuladas en Europa por el populismo romántico y en América Latina por el nacionalismo y el indigenismo conservadores, y, por otra parte, del positivismo que, preocupado por el rigor científico, olvidó el sentido político de la producción simbólica del pueblo" (García Canclini, 2002: 91).
} 
la cultura popular y hasta dónde se "contamina" con la cultura de masas, incluso con la cultura de élite? ¿Cómo comprender en los regímenes del percibir y del expresar audiovisuales modernos y las nuevas tecnologías de la imagen los rastros y trayectorias de las manifestaciones de la cultura popular, como los carnavales?

Los hallazgos de estos estudios deberán formar parte de programas de educación, no como una electiva más o "cultura general", sino como práctica, proceso, episteme, transmisión, realización, creación, intervención en el mundo local, regional, nacional e internacional. El carnaval como un texto de enseñanza-aprendizaje, a la vez formativo, informativo y creativo. Texto básico, en suma, para pensar y vivir la identidad/diferencia nacional, no la "cultura nacional". Ya es hora de que la cultura popular, sus estéticas y sus producciones artísticas (el arte de masas ya está) entren definitiva y contundentemente en la escuela y la universidad, o si se me permite la metáfora en otra dirección, la escuela y la universidad deben abrir las puertas para que los saberes y sus prácticas de la cultura ilustrada salgan a vivir la diversidad que propone el carnaval. Desde la referencia puntual que hice al inicio, sería la nación de los pueblos pastos, quillasingas, tumacos...

\section{Bibliografía}

Bajtín,Mijail.(1974). La cultura popular en la Edad Mediayen el Renacimiento. Barcelona: Barral Editores.

Bajtín, Mijail. (1996). "El cronotopo" en Teoría de la novela: antología de textos del siglo XX. Barcelona: Crítica Grijalbo Mondadori.

Martín BarberoJesús. (2003). Oficio de Cartógrafo:travesíaslatinoamericanas de la comunicación en la cultura. México: Fondo de Cultura Económica.

Martín Barbero Jesús y Rey, Germán. (1999). Los ejercicios del ver: hegemonía audiovisual y ficción televisiva. Barcelona: Gedisa.

Benjamín, Walter. (1973). "La obra de arte en la época de la reproducibilidad técnica" en Discursos Interrumpidos. Madrid Taurus. (Traducción de J. Aguirre).

Escobar, Ticio. (2003). “Estética de las Artes populares" en Estética. Madrid: Editorial Trota. (Edición de Ramón Xirau y David Sobrerilla).

García Canclini, Néstor. (2002). Culturas populares en el capitalismo. México: Grijalbo.

Gutiérrez Estévez, Manuel. (1989). "Una visión antropológica del carnaval” en Huerta Calvo, Javier. (Comp.) Formas carnavalescas en el arte y la literatura. Barcelona: Ediciones del Serbal.

Marchán Fiz, Simón. (2001). Del arte objetual al arte de concepto. Madrid: Akal.

Montaño, Ramón. (s.f.) "Arte performance" en http://www.geocities.com/ festivaldeartealternativo/Performance.html 
Julio César Goyes Narváez

Marthe, Robert. (1972). "Anotaciones en torno a la exégesis de Freud" en Revista Eco, no 164, (noviembre), pp. 43-72

Sarikartal, Cetil. (2005). "Shock, mirada y mimesis: la posibilidad de un enfoque preformativo sobre la visualidad" en Estudios Visuales: la epistemología de la visualidad en la era de la globalización. Madrid: Akal. (Edición de José Luís Brea).

Taylor, Diana. (s.f.). “Hacia una definición de performance"en: http:// hemi.nyu.edu/course-rio/perfconq04/materials/text/ Haciaunadefinic_DianaTaylor.htm 